面, 形成混有細菌細胞的乳白色薄膜, 大小为 $0.3 \times$ 1一微米。

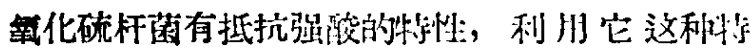

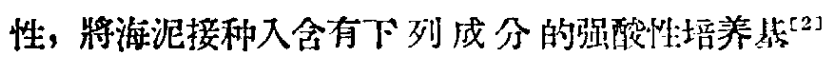
中: 硫少 $1 \% ;\left(\mathrm{NH}_{4}\right)_{2} \mathrm{SO}_{4} 0.62 \% ; \mathrm{KH}_{2} \mathrm{PO}_{4} 0.4 \%$; $\mathrm{MgSO}_{4} \cdot 7 \mathrm{H}_{2} \mathrm{O} 0.05 \% ; \mathrm{CaCl} 0.025 \% ; \mathrm{FeSO}_{4} \cdot 7 \mathrm{H}_{2} \mathrm{O}$ 微量; 水 100 毫扑; $\mathrm{PH} 2-3.5$ 。在 $25-30^{\circ} \mathrm{C}$ 混 箱中进行淺层唔养, 2-3天或更髟一些的时间后，塔 养液反应降低到 PH2 或便低, 均匀混濁, 印可取培养 液少鸽，接种入与上述成分相同新的液体培养基中，

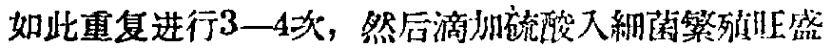
的培养液中，使塔养液反应降低到 PHO.6或这低, 以此方法滛汰杂菌, 倾诃得到純培养。此外, 利川稀 翠法也能得純培养。此种純培养的主要特征与排硫杆

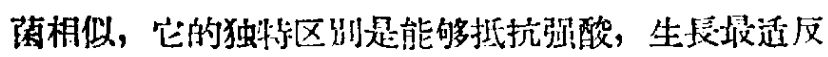
应是 PH2-3.5, PH 值等于: 0.6 或近低时也不做將 它杀死, 是文献中报告过的最能抵抗强酸的微生物, 无馅子, 能运动, 革闌纸染色保反应, 大小为 $0.5 \times$ 1.0微米。

瞈氮硫杆菌是朋含有下列成分的培养基 ${ }^{[3]}$ 分离 的: $\mathrm{Na}_{2} \mathrm{~S}_{2} \mathrm{O}_{8} \cdot 5 \mathrm{H}_{2} \mathrm{O} 0.5 \% ; \mathrm{KH}_{2} \mathrm{PO}_{4} 0.2 \% ; \mathrm{KNO}$ \& $0.2 \%$, $\mathrm{NaHCO}_{3} \quad 0.1 \% ; \mathrm{MgSO}_{4} \cdot 7 \mathrm{H}_{2} \mathrm{O} \quad 0.6 \%$; $\mathrm{NH}_{4} \mathrm{Cl} 0.05 \% ; \mathrm{FeSO}_{4} \cdot 7 \mathrm{H}_{2} \mathrm{O} 0.001 \%$; 水 100 毫升; PH 7.1-7.6。方法是將海汁接种入充萠上述唔养液 的玻举錐形瓶中, 在 $25-30^{\circ} \mathrm{C}$ 溫箱中进行培养, 一 直到有气池自瓶低部沉促中上外，川白金絲酸取培养

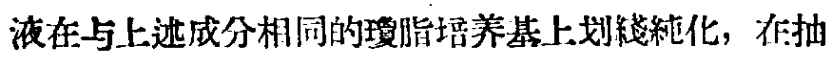

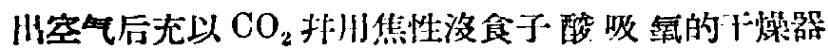

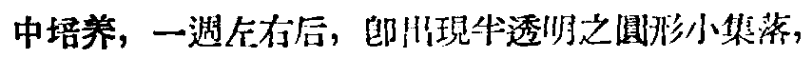
取單一集落重复划綫純化便叮得到純培养。純培养的

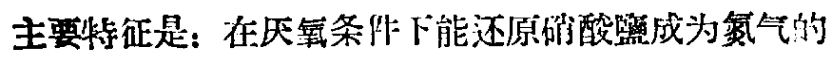

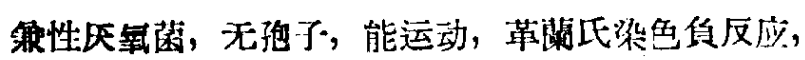
大小为 $0.5 \times 1-3$ 微米。

在硫杆菌的生命话动中所进行的硫化作: $\{$ \}; 能使 硫或硫的不完全氧化物轉化成为硫酸等产物, 作士流

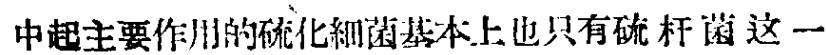

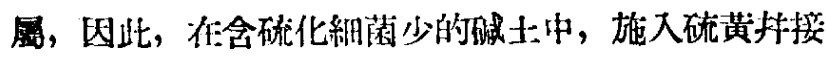
种适当的硫杆菌, 对强碱土的改良是会产生有豃效闸 的。关于利胉这种細菌改良碱七的誠噞正在进行中。 我們所分离的硫杆菌, 还可以作为勘㤾硫矿、铁 矿、銅矿的标准指示藏 ${ }^{[4]}$ 。

\section{薪廷耀孙国玉 (中国科学院海洋研究所)}

[1] Vishniac, W. and Santer, M., 1957, Bacteriol. Rev., 21:195-213.

[2] Starkey, R. L., 1935, Soil Sei., 39: 157-219.

[3] Baalsrud, K. and Baalsrud, K. S., 1954, Areh. für Mikrobiol., 20:34-62.

[1] Starkey, R. L., 1956, Ind. Eng. ¿Chem., 48: 1429-1437.

\section{关于海带配子体的排卯和排精 現象及精子的形态"}

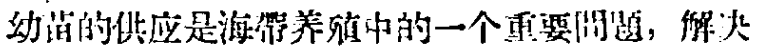

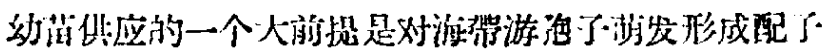
体到发生抱子体这一阶段的系統了解。由于要准确地

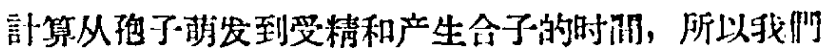
就观察了配子一体排卵和排精的現象。

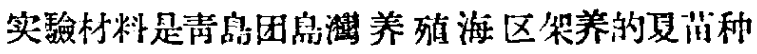

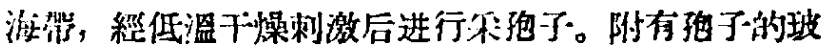

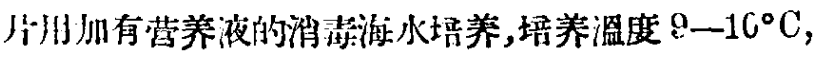

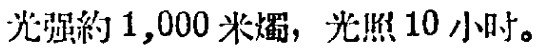

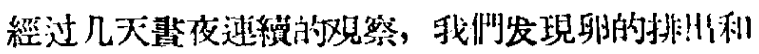

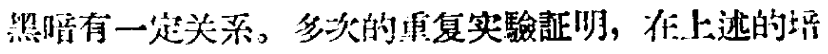

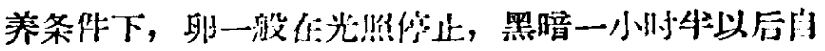

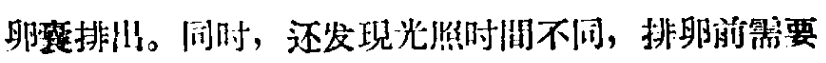

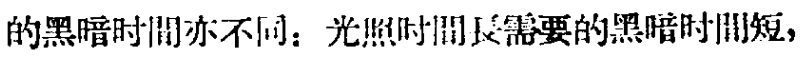

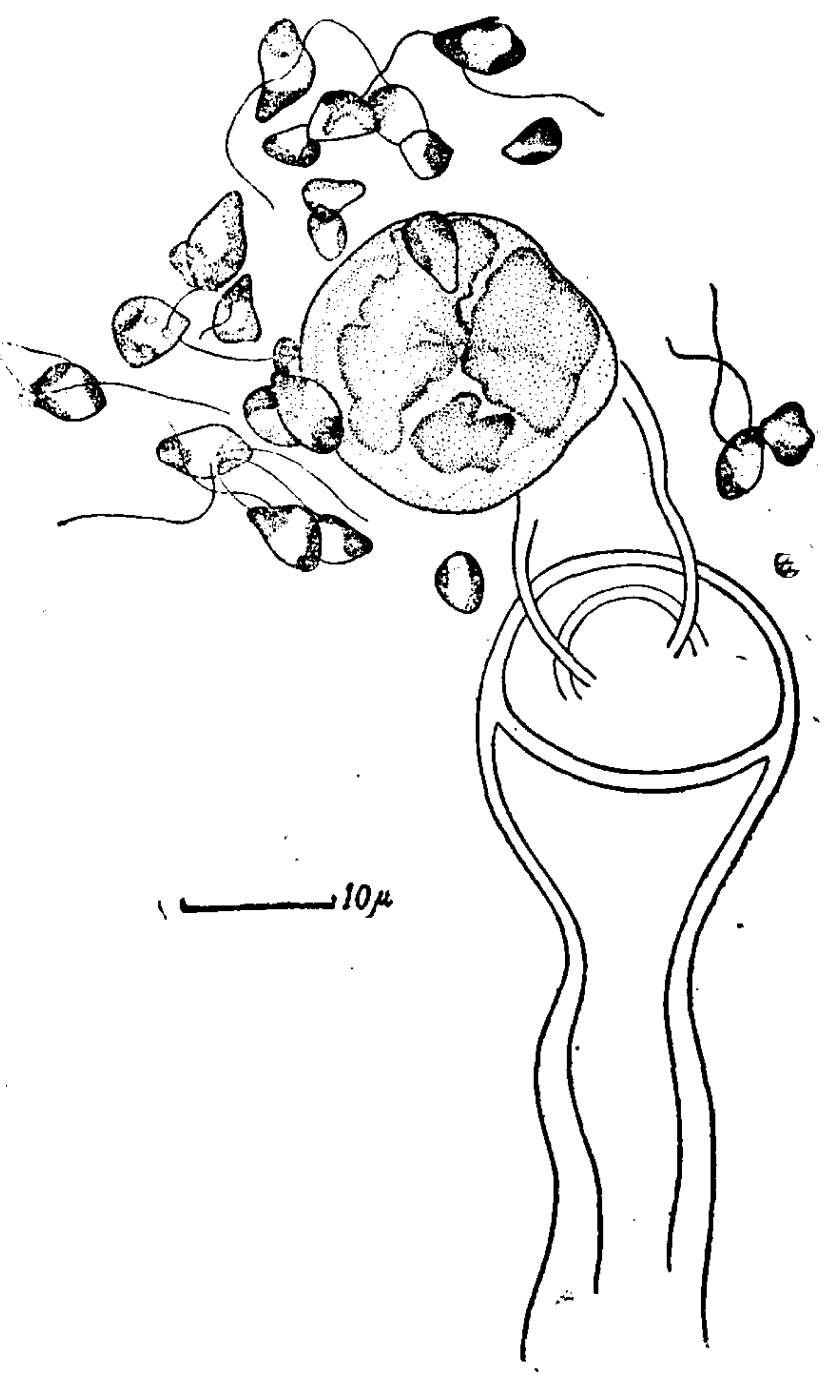

图 1 甽排出的卵和果中到卵务的精子

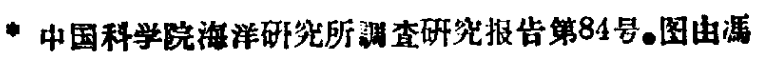
明华同志所粮，特此效謝。 


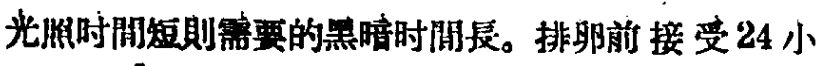
时光烦的配子体只需 20 分 銅 左右的墨暗时间就能排 躬，而兒光 1 小时的配子体则需要 3 小时以上的黑暗

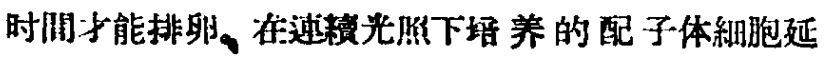

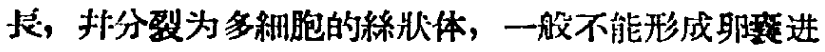

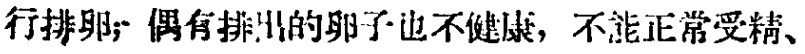
发有为幼色了?体。

排精現象是与排卵问时进行覌祭的。多次观睍祭的 絬果，发現排精一与排卵有密切的关系。一般是卵先排 出，不久趴有大量精子很 快的从附近的精了整中排

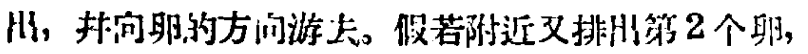
一部精子·会很块的轉问新率。这些現像和 Mo 2wus 等: 人研究骂胞藻配子接合时所发現的現侄相类似。

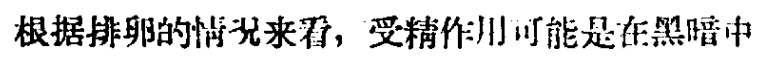
进行的, 未目是卵了排出后找进行的。在有光秋涤件:

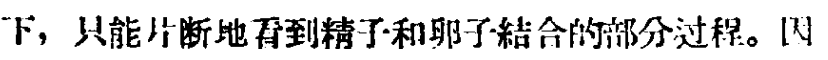

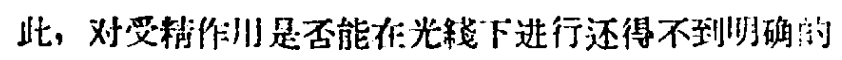
絬稀。
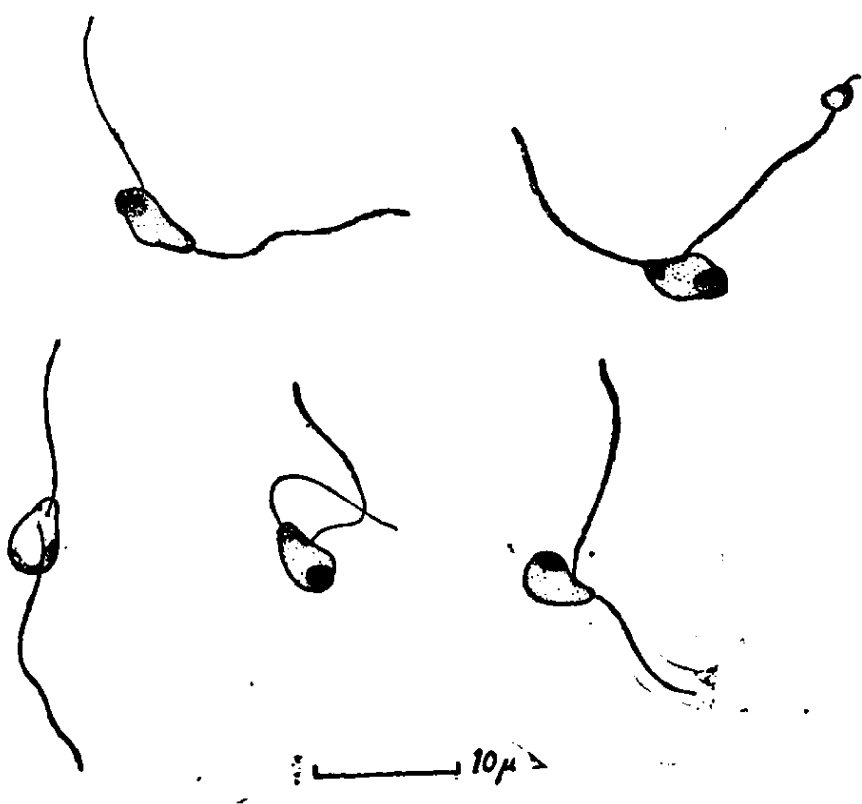

图 2 带的精子

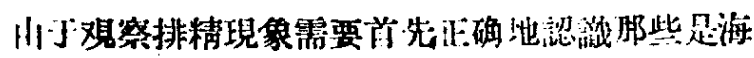

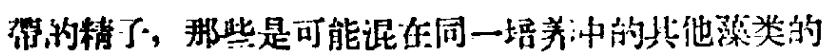
孢了, 我阿对精子的形态监作了一些覌察。川解酸固 北的精了为梨形，大小为宽 $2.7-3.4 \mu$ ，重 $4.4-6.2 \mu$ ； 䩿毛爾条, 侧生, 不等長, 前面一条長 13.7-16 $\mu$, 后面一条長 $16-19 \mu$ ，在后部的䩒巨上經常附着一个 类似色素粒的球狀体，位疽不固定，有的作䩒飞基 部, 有的在鞭毛尖端; 球狀体有时在精子游泳一定时 間之后, 即行眖落。

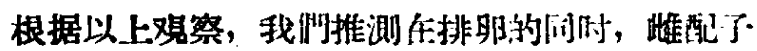

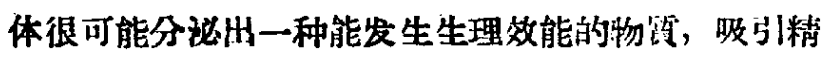
了“游向眆护促使精卵互相結合。

\section{星是查 任国忠 吴超元

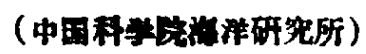

\section{赤露酸及其他植物生長刺激暴 对海带生長的影响"}

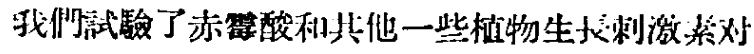

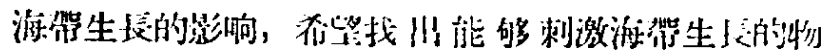

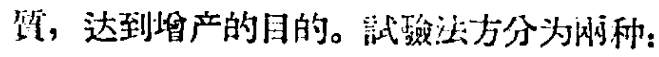

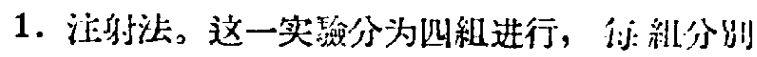

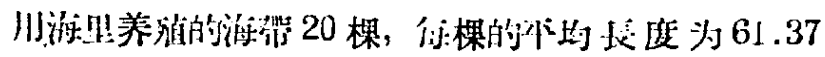

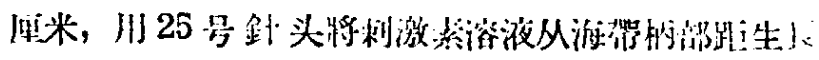

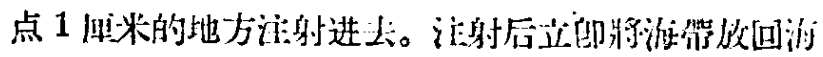

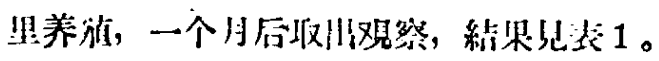

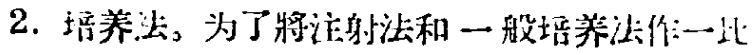

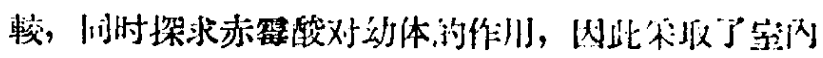

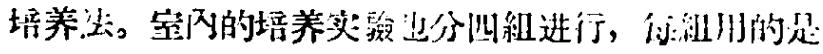

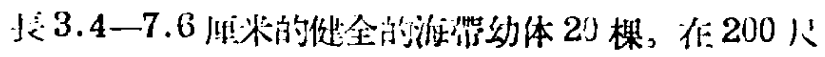

，11-12 小时的光留和 $10-18^{\circ} \mathrm{C}$ 的学滥环境下，

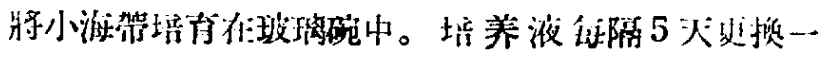

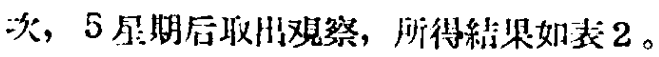

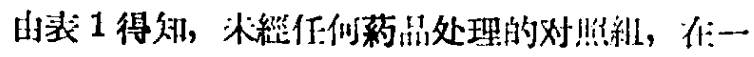

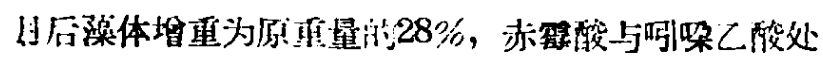

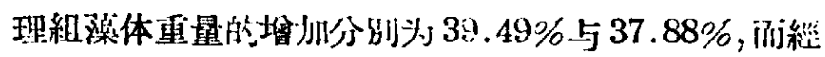

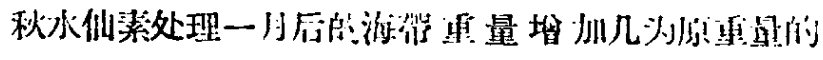

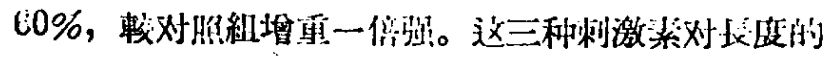

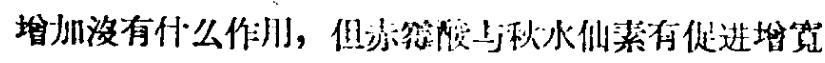

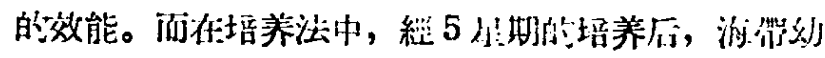

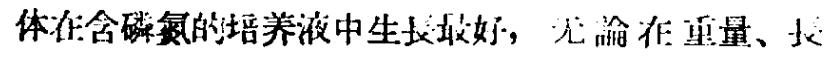

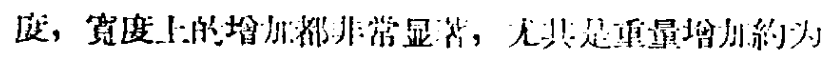

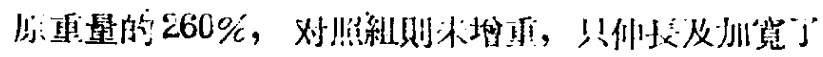

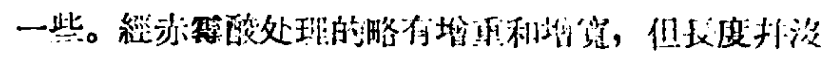

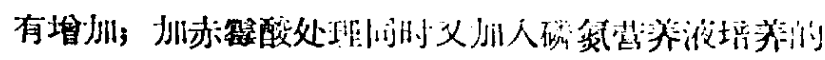

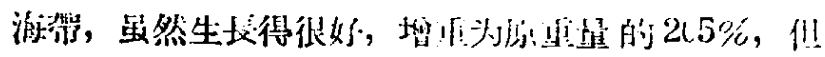

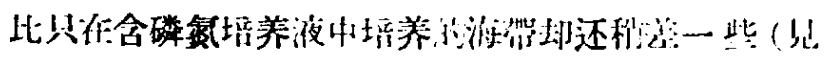
表2)。

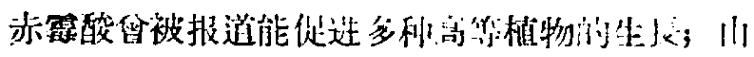

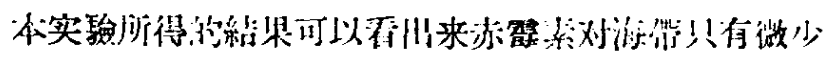

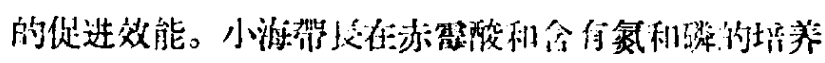

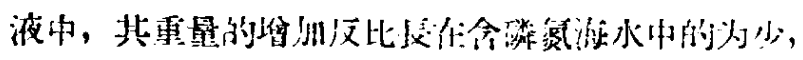

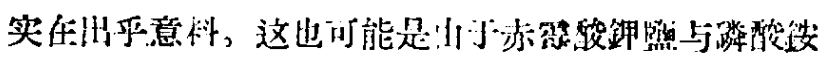

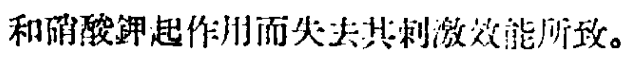

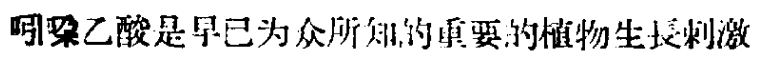

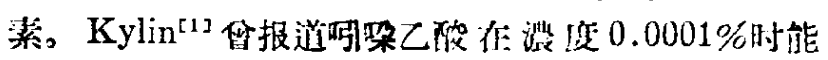

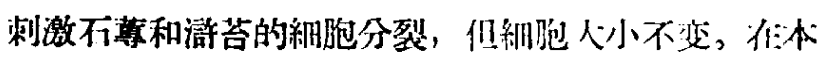

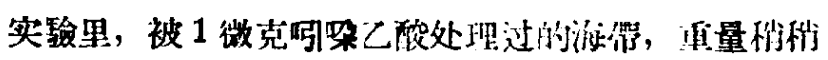

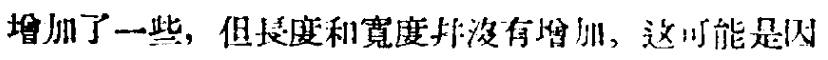
为所用的分量不合适的絞故。

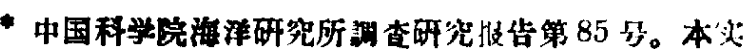

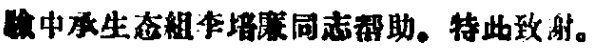

